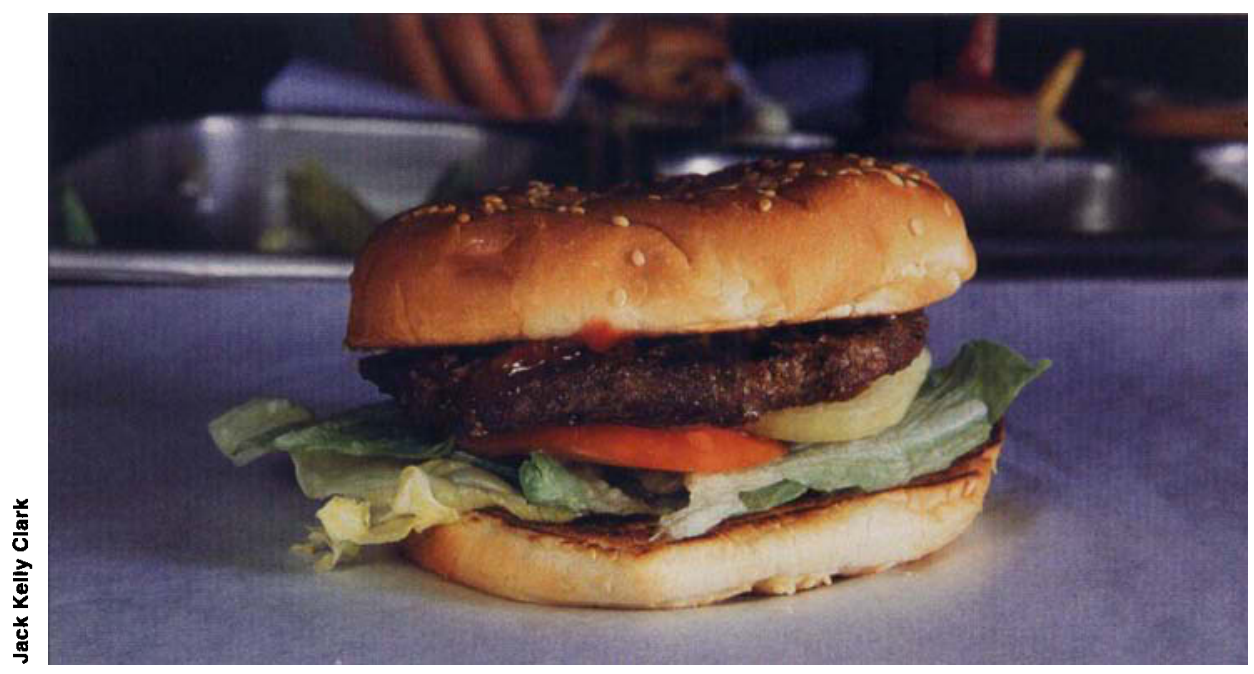

As part of a multistate project, 200 Californians were asked about the roles of fat and fiber in the diet and their own consumption practices. Nearly all of the people surveyed said concerns about health and weight influenced what they ate.

\title{
Californians' eating habits differ from their dietary attitudes
}

\author{
Christine M. Bruhn $\square$ Dana Wong $\square$ Howard G. Schutz
}

\begin{abstract}
While California consumers are knowledgeable about general dietary recommendations, a recent survey found many are not aware of the recommended daily servings of fruit and vegetables, and do not always follow through on meal-time practices to lower dietary fat and increase fiber. Nutrition education should be targeted to correct misunderstandings about diet, and emphasize the values of eating fruit and vegetables and exercising to maintain good health.
\end{abstract}

National surveys indicate that more than $80 \%$ of Americans are concerned about the effects of diet on health. In the last 10 years, up to two-thirds of Americans said they had reduced their fat consumption, were eating less meat and more poultry, and eating more fruits and vegetables. However, marketplace consumption figures suggest that consumers may have overstated their compliance with dietary guidelines.

As part of a multistate project, a questionnaire was developed addressing consumer's knowledge and understanding of types of fats, sources of fats and fibers, consumption practices, and knowledge and adherence to the dietary guidelines for Americans established by the U.S. Department of Agriculture and U.S. Department of Health and Human Services. The questionnaire also identified con- straints and motivating factors influencing dietary consumption changes.

The questionnaire, which was designed by scientists and evaluated by nutrition experts, was pilot-tested, and revised twice. Final question-

\begin{tabular}{|c|c|c|c|}
\hline & & Respondents & California \\
\hline & & ............... & (n......... \\
\hline \multicolumn{3}{|c|}{ Highest level of education $(n=200)$} & . \\
\hline & Grade school or some high school & 6 & 15 \\
\hline & High school graduate or GED & 18 & 30 \\
\hline & Some college / trade or vocational school & 34 & 35 \\
\hline & College graduate & 25 & 20 \\
\hline & Graduate work & 17 & 10 \\
\hline \multicolumn{4}{|c|}{ Present marital status $(n=200)$} \\
\hline & Married or living together & 68 & 52 \\
\hline & Separated, Divorced & 15 & 12 \\
\hline & Widow / Widower & 4 & 6 \\
\hline & Never Married & 13 & 30 \\
\hline \multicolumn{4}{|c|}{ Age $(n=200)$} \\
\hline & $18-24$ years & 2 & 6 \\
\hline & $25-39$ & 22 & 35 \\
\hline & $40-49$ & 25 & 20 \\
\hline & $50-64$ & 24 & 20 \\
\hline & 65 and older & 27 & 19 \\
\hline \multicolumn{4}{|c|}{ Gross annual household income $(n=188)$} \\
\hline & less than $\$ 10,000$ & 5 & 12 \\
\hline & $\$ 10,000-\$ 19,999$ & 11 & 15 \\
\hline & $\$ 20,000-\$ 29,999$ & 16 & 15 \\
\hline & $\$ 30,000-\$ 39,999$ & 16 & 13 \\
\hline & $\$ 40,000-\$ 49,999$ & 14 & 12 \\
\hline & more than $\$ 50,000$ & 38 & 33 \\
\hline \multicolumn{4}{|c|}{ Ethnicity $(n=199)$} \\
\hline & White / Caucasian / Angio & 81 & 62 \\
\hline & Hispanic / Latino & 7 & 16 \\
\hline & Asian / Asian American & 6 & 7 \\
\hline & Black / African-American & 4 & 7 \\
\hline & Other & 2 & 8 \\
\hline
\end{tabular}




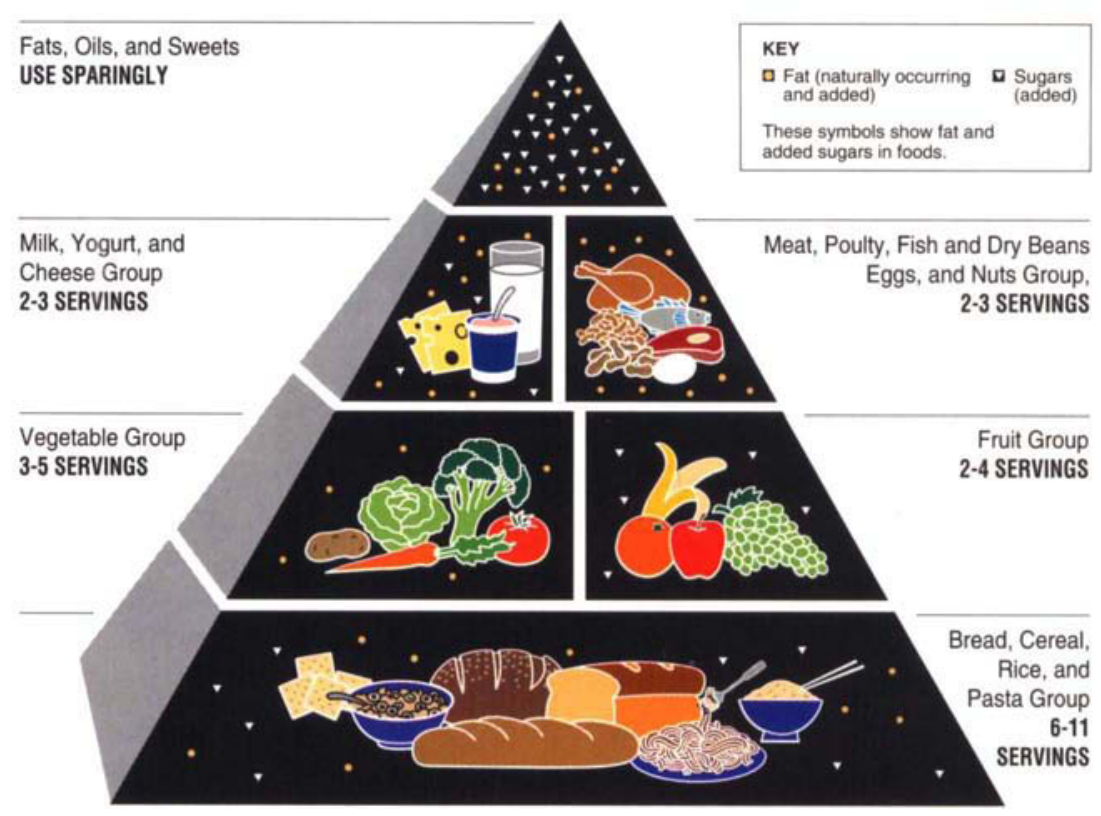

naires and postage-paid return envelopes were mailed in 1993 to a statistical sample of California households, with 300 questionnaires sent to women and 300 to men 18 years or older. Sample size was proportionate to the population in each zip code. Survey participation was voluntary and confidential. Of 600 surveys distributed, 205 usable questionnaires were returned with an adjusted return rate (discounting undeliverable questionnaires) of $42 \%$.

\section{Respondents primarily Caucasian}

The gender and age ranges of the sample were evenly distributed. However, the majority of respondents were Caucasian, and formal education was higher than the state average (table 1). Three-quarters had at least some college education and most were currently employed. The sample included both urban and rural residents, and income was evenly distributed. In terms of health, $20 \%$ indicated they had been diagnosed with high blood pressure and $17 \%$ with high blood cholesterol. Less than $10 \%$ listed other conditions such as cancer or diabetes; some people may have had diseases without their knowledge. More than $80 \%$ did not follow a special diet for health reasons and the majority considered their health good or excellent.

\section{Factors influencing diet}

Nearly all (97\%) of the respondents said concerns about health and weight influenced what they ate, with $58 \%$ indicating health and $45 \%$ noting that weight strongly influenced their dietary choices. Over half (54\%) said food likes and dislikes played an important role in what they ate, $39 \%$ listed spouse influence, and 34\% preparation time. Almost one-quarter said the cost of food influenced their food choice; however, almost threefourths believed that eating healthier does not cost more.

The majority indicated they had made changes to improve their health and weight. These changes included reading the label for fat and choles-

Fig. 1. The Food Guide Pyramid: A guide to daily food choices. Source: U.S. Department of Agriculture/U.S. Department of Health and Human Services

terol content, eating more fruits and vegetables, and reducing the amount of fat in their diet (table 2).

\section{Diet and health beliefs}

Although respondents were concerned about links between nutrition and disease, most rated other factors, such as family history and obesity, as more influential in developing cancer or heart disease (table 3). Only onethird ranked poor diet as very important in developing cancer; smoking and family history were correctly ranked highest. More than $90 \%$ strongly agreed or agreed that they were more likely to get heart disease if there was a lot of fat or saturated fat in their diet. The value of produce and grains seemed well accepted, with $85 \%$ agreeing that eating plenty of vegetables, fruits, and grain products would reduce their chance of getting heart disease. Conversely, only $57 \%$ believed that eating plenty of fiber would reduce the risk of heart disease.

Health authorities note there are both pro- and anticarcinogenic properties from dietary fat. About half of the respondents $(52 \%)$ believed consuming a high-fat diet increases the risk of getting cancer. More than two-thirds correctly recognized they may reduce the likelihood of getting cancer by eating plenty of vegetables, fruits, grain products and fiber. Respondents also

\begin{tabular}{|c|c|c|c|}
\hline \multicolumn{4}{|l|}{ Compared to a few years ago, how often do you ...? } \\
\hline & More & Less & $\begin{array}{l}\text { Number of } \\
\text { respondents }\end{array}$ \\
\hline \multicolumn{4}{|c|}{........................ } \\
\hline Read fat and/or cholesterol content of food labels & 70 & 4 & 195 \\
\hline Eat vegetables & 63 & 4 & 205 \\
\hline Trim fat off meat & 62 & 8 & 191 \\
\hline Eat fruits & 62 & 3 & 205 \\
\hline Cook with vegetable oils & 58 & 10 & 196 \\
\hline Use skim milk or nonfat dried milk & 55 & 10 & 169 \\
\hline Decrease fat and oil in recipes & 52 & 14 & 200 \\
\hline Eat cereal/grains & 52 & 3 & 199 \\
\hline Broil meats, fish, poultry & 46 & 8 & 194 \\
\hline Barbecue meats, fish, poultry & 30 & 22 & 188 \\
\hline Use egg substitutes and/or egg whites instead of whole eggs & 22 & 19 & 149 \\
\hline Add cheese to your food & 8 & 40 & 193 \\
\hline Add sour cream & 7 & 53 & 163 \\
\hline Add butter/margarine to food & 5 & 48 & 197 \\
\hline Eat foods with gravy & 3 & 54 & 180 \\
\hline
\end{tabular}


TABLE 3. California consumers' attitudes toward influences of diet on health

Do you think foods you eat put you at risk for...?

\begin{tabular}{|c|c|c|c|}
\hline Yes & No & Don't know & $\mathbf{n}$ \\
\hline 88 & 7 & 5 & 203 \\
\hline 68 & 16 & 16 & 200 \\
\hline
\end{tabular}

Heart Disease

68

200

How important are the following things in increasing your chances of developing heart disease?

\begin{tabular}{lr} 
Very important \\
\hline$\ldots \ldots \ldots \ldots \ldots \ldots \ldots \ldots \ldots \ldots \ldots \ldots \ldots \ldots \ldots$ \\
82 & 8 \\
75 & 15 \\
70 & 14 \\
53 & 25 \\
49 & 27
\end{tabular}

$\mathbf{n}$

\section{Smoking}

Obesity

Family History

Exercise
Not important

7
6
8
18
17

1
3
2
3

3
How important are the following things in increasing your chances of developing cancer?

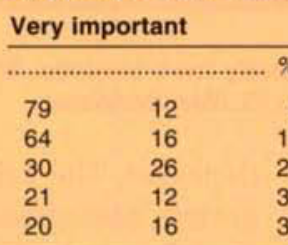

TABLE 4. Californians' knowledge about fat, saturated fat and fiber

\section{Correct}

n

$\%$

For each food pair, which food is higher in fat?

Chicken with skin" vs chicken without skin

Brownie* vs angel food cake

Butter vs regular margarine

Hamburger* vs turkey

Potato chips* vs pretzels

$\begin{array}{ll}91 & 20 \\ 74 & 20 \\ 66 & 20 \\ 92 & 20 \\ 82 & 20\end{array}$

For each food pair, which food is higher in fiber?

Raw apple* vs apple juice

Boiled or refried beans" vs mashed potatoes

Bran flakes* vs cornflakes

Popcorn* vs potato chips

$92 \quad 203$

$70 \quad 203$

85

$80 \quad 203$

For each food pair, which food is higher in saturatedfat?

Butter* vs margarine

Hamburger* vs peanut butter

Lard or shortening ${ }^{*}$ vs vegetable oil

Coconut oil ${ }^{*}$ vs corn oil

Broiled steak* vs broiled fish

- signifies correct answer

TABLE 5. Diet change decisions based on better health

If it were good for your health, would you ...?

\begin{tabular}{lcc} 
& Yes & $\mathbf{n}$ \\
\hline & $\%$ & 205 \\
Eat more fruits/vegetables & 94 & 203 \\
Trim fat from meat & 93 & 203 \\
Use whole-grain breads & 91 & 202 \\
Take skin off poultry & 88 & 202 \\
Eat fewer desserts/pies & 83 & 203 \\
Use 1\% skim milk & 79 & 204 \\
Use margarine instead of butter & 77 & 202 \\
Use egg whites instead of whole eggs in baking & 53 & \\
\hline
\end{tabular}

agreed that eating plenty of vegetables, fruits, and grains could reduce the frequency of intestinal problems. Consumers were more apt to recognize the relationship between dietary fat and heart disease than dietary fiber and cancer.

\section{Knowledge about diet guidelines}

While the respondents' ability to recognize USDA dietary recommendations was good, our survey found that the majority did not know specifics about the recommended number of daily servings. Only $34 \%$ knew they should eat five or more servings of fruits and vegetables daily, only $6 \%$ were aware that dietary guidelines recommend six to 11 servings of breads, cereals, pastas and rice daily, and $21 \%$ were aware of specific fat restrictions. Although many food labels display the food pyramid (fig. 1), consumers appear not to understand recommendation details. More emphasis is needed on the recommended number of servings in each category.

Consumers were knowledgeable about relative fat content of several common foods. Most were able to correctly distinguish which foods had more fat, saturated fat, or fiber (table 4). More than $90 \%$ knew that chicken with skin had more fat than chicken without, and hamburger had more fat than turkey. About three-quarters recognized brownies were higher in fat than angel food cake, and potato chips higher than pretzels. In contrast, less than one-quarter recognized there is no difference in fat level between butter and margarine.

Knowledge of sources of saturated fat was also good (table 4). More than $70 \%$ of respondents knew butter, lard/ shortening and coconut oil were higher in saturated fat than margarine, vegetable oil and corn oil, respectively. More than four-fifths identified broiled steak as higher in saturated fat than broiled fish. Over half knew hamburger contains more saturated fat than peanut butter.

Consumers were unaware of sources of dietary cholesterol. Two- 
thirds knew cholesterol came from animal products such as meat and dairy; however, almost one-third incorrectly responded that all food containing fat or oil contains cholesterol.

Respondents' knowledge of relative fiber content was commendable (table 4). More than two-thirds $(70 \%)$ knew boiled or refried beans are higher in fiber than mashed potatoes. The majority also identified popcorn and bran flakes as higher in fiber than potato chips and cornflakes, respectively. Ninety-two percent knew raw apple had more fiber than apple juice.

\section{Changing dietary practices}

Respondents indicated a willingness to adopt new strategies to reduce dietary fat and increase dietary fiber to improve health (table 5). Despite good

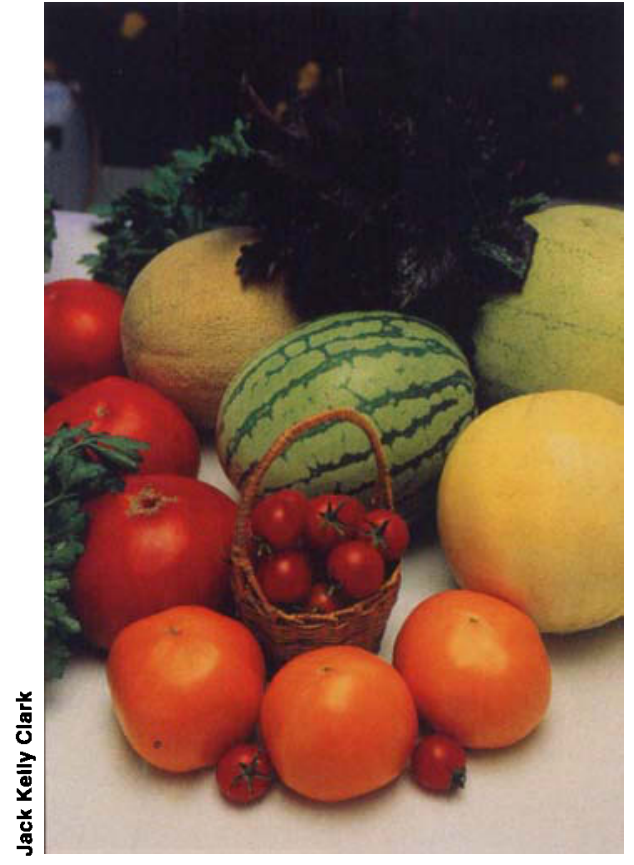

Only $34 \%$ of the respondents knew USDA dietary guidelines recommend eating five or more servings of fruits and vegetables daily.

\begin{tabular}{|c|c|c|c|}
\hline In the last month, how often did you ...? & $\begin{array}{l}\text { Always } \\
\text { or often }\end{array}$ & Never & $\begin{array}{r}\text { No. of } \\
\text { responses }\end{array}$ \\
\hline Meat, fish, poultry & \multicolumn{2}{|c|}{ 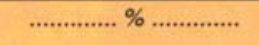 } & \\
\hline Eat fish or chicken instead of red meat & 75 & 5 & 198 \\
\hline Trim all visible fat from red meat & 66 & 16 & 199 \\
\hline Eat baked or broiled chicken & 61 & 11 & 202 \\
\hline Eat chicken with skin removed & 59 & 17 & 202 \\
\hline Eat small portions of red meat & 55 & 25 & 204 \\
\hline Use meatless tomato sauce on spaghetti/noodles & 35 & 38 & 200 \\
\hline Have a vegetarian dinner & 31 & 39 & 198 \\
\hline \multicolumn{4}{|l|}{ Dairy } \\
\hline Use very low-fat ( $1 \%)$ or nonfat milk & 67 & 22 & 200 \\
\hline Eat ice milk, frozen yogurt or sherbet instead of ice cream & 36 & 34 & 200 \\
\hline Eat special, low-fat, diet cheeses & 29 & 44 & 200 \\
\hline Use yogurt instead of sour cream & 28 & 58 & 201 \\
\hline \multicolumn{4}{|l|}{ Use of added fats } \\
\hline Use low-calorie instead of regular salad dressing & 44 & 30 & 202 \\
\hline Use diet, low-calorie mayonnaise instead of regular mayonnaise & 43 & 43 & 201 \\
\hline Use Pam or other nonstick spray when cooking & 42 & 34 & 204 \\
\hline Put butter or margarine on cooked vegetables & 42 & 31 & 202 \\
\hline Eat breads, rolls, or muffins without butter or margarine & 40 & 34 & 203 \\
\hline Eat green salad with low-calorie, diet dressing & 39 & 31 & 199 \\
\hline Eat broiled or baked potatoes without butter & 25 & 50 & 204 \\
\hline Eat only fruit for dessert & 28 & 32 & 198 \\
\hline Put sour cream, cheese, or other sauces on vegetables and potatoes & 21 & 45 & 202 \\
\hline Eat green salad without dressing & 14 & 68 & 202 \\
\hline \multicolumn{4}{|l|}{ Fruits, vegetables, and high fiber foods } \\
\hline Eat broiled or baked potatoes with the skin & 69 & 12 & 201 \\
\hline $\begin{array}{l}\text { Eat breads, rolls, or muffins made from whole grains } \\
\text { (whole wheat, rye) }\end{array}$ & 64 & 13 & 202 \\
\hline Eat cereal for breakfast & 61 & 16 & 198 \\
\hline Eat raw fruits for snacks & 53 & 11 & 199 \\
\hline Eat fruit for breakfast & 46 & 25 & 199 \\
\hline Eat at least two vegetables (not green salad) at dinner & 44 & 15 & 204 \\
\hline Eat beans, peas, or lentils as a vegetable or main course & 35 & 29 & 201 \\
\hline Snack on raw vegetables instead of potato, corn, taco chips & 34 & 31 & 203 \\
\hline Eat a vegetable (not green salad) at lunch & 30 & 32 & 199 \\
\hline Eat raw vegetables for snacks & 30 & 36 & 201 \\
\hline
\end{tabular}

intentions, however, not all reported following these strategies. For example, $93 \%$ had indicated they would be willing to trim fat from their meat, $66 \%$ said they follow this practice (tables 5 and 6). About $90 \%$ said they would remove the skin from poultry, but only $59 \%$ reported doing so always or often. Correspondingly, $78 \%$ said they would use skim milk, but only $67 \%$ reported using this low-fat product.

Meat, fish, and poultry consumption. Many respondents reported using lower fat preparation methods (table 6). More than half said they "always or often" baked or broiled chicken and removed the chicken skin prior to consumption. Almost threequarters said they usually or often eat fish or chicken instead of red meat and two-thirds trimmed all visible fat from red meat. The per-capita consumption reported in Agricultural Outlook confirms that U.S. consumption of red meat has dropped, with beef consumption dropping 12.9 pounds per person and poultry consumption increasing 16 pounds per person from 1985 to 1993.

Most people reported they had reduced, but not eliminated, meat/poultry consumption. Almost $40 \%$ said they had never eaten a vegetarian meal or used a meatless tomato sauce. Only about $31 \%$ reported having a vegetarian dinner.

\section{Milk and cheese consumption.}

Californians were reducing dairy fat consumption by selecting nonfat or low-fat milk, but were not switching to other lower-fat dairy products.

Two-thirds said they often drank very low-fat $(1 \%)$ or nonfat milk (table 6 ). Low-fat cheeses, however, were used less often. Similarly, respondents rarely substituted yogurt for sour cream when cooking. Only one-third said they often substitute lower-fat, frozen desserts for ice cream.

Fats and oils consumption. Less than half $(42 \%)$ said they always or often add butter or margarine to vegetables, and only $20 \%$ always or often add sour cream, cheese or other sauces 


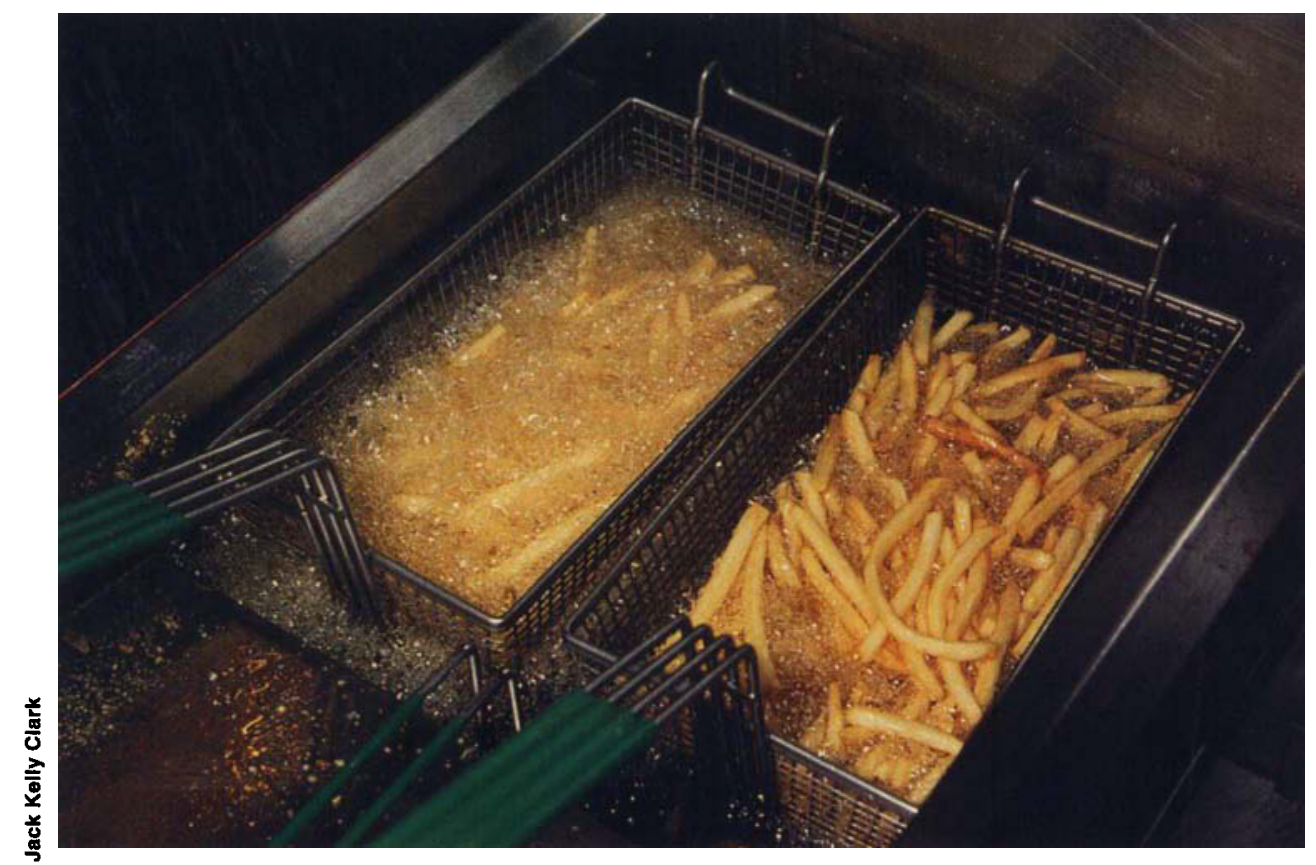

To improve their health and weight, the majority of people indicated they had changed their eating habits, including reducing the amount of fat in their diets. However, $54 \%$ said food likes and dislikes played an important role in what they ate.

(table 6). Forty percent always or often ate bread products without butter. About two-thirds (68\%) said they rarely eat a green salad without dressing; however, almost half always or often use a low-calorie dressing, lowcalorie mayonnaise, or nonstick spray when cooking.

Despite these statements, per-capita consumption reported in Agricultural Outlook showed no significant changes in total consumption of butter/margarine, shortening or salad/cooking oils.

Fruits, vegetables and salad consumption. Two-thirds of respondents said they were eating more fruits and vegetables than in the past (table 2), but less than half ate two vegetables at dinner (excluding a salad), and less than one-third ate vegetables at lunch (excluding lettuce). One-fourth said they rarely ate fruit with breakfast and one-third said they rarely ate raw vegetables as a snack. Raw fruits were more popular, eaten as snacks by about half of respondents.

While respondents reported consuming more fruits and vegetables, nationwide per-capita consumption data show an insignificant increase. Vegetable consumption has increased by less than one pound per year per person and fruit consumption also dropped from 1989 to 1991 . This suggests Californians may be responding with the "right" answer rather than the answer reflecting actual behavior.

Whole-grain bread products were eaten by almost two-thirds of respondents (table 6). Similarly, almost twothirds said they often ate cereal for breakfast, and ate potatoes with the skins. Most said they rarely served beans, peas, and lentils as a main course.

\section{Exercise and health}

Routine exercise, along with a healthy diet, can reduce the risk of heart disease. More than three-fourth of respondents believe lack of exercise contributes to the development of heart disease, with more than half finding it a very important factor.

\section{Consumer attitudes}

Consumer responses do not always reflect scientific fact. For example, about one-third of those surveyed consider exercise important in preventing cancer; however, this relationship has not been supported by scientific studies. Additionally, $16 \%$ believe dietary fat is related to bone problems; again, there is no scientific support for this statement.

Survey responses also may reflect the views, but not necessarily the be- havior, of a more health-conscious population. For example, California respondents report consuming $1 \%$ or nonfat milk at a higher rate than sales indicate, suggesting we had a disproportionate number of diet-conscious people among our respondents or they incorrectly estimated their dietary practices.

Our findings demonstrate that a segment of Californians:

- Recognize the important role of diet in health, especially as it relates to heart disease and certain cancers.

- Read labels more frequently.

- Trim fat from meats and skin from poultry.

- Believe they decreased fat and oil consumption.

- Believe they ate more fruits and vegetables.

Results clearly revealed areas for focused health education:

- Consumers recognized the four food groups, but could not identify the daily recommended number of servings. Dietary guidelines should encourage increased consumption of breads/grains and fruits and vegetables.

- People need to be encouraged to eat more produce, both at meals and as a healthy, between-meal snack.

- Consumers were misinformed about fat and cholesterol. Nutritional education should dispel misconceptions about butter and margarine fat levels and encourage consumption of less total fat.

- People should be reminded that lean meat can be part of a healthy diet.

- Californians still underestimate the health benefits of regular exercise. Along with dietary education, the importance of regular exercise must be emphasized.

C.M. Bruhn is Consumer Food Marketing Specialist, Center for Consumer Research, UC Davis; D. Wong is Sensory Technologist, The National Food Laboratory, Dublin; H.G. Schutz is Professor Emeritus, Department of Food Science and Technology, UC Davis. 